\title{
Customization and variants in terms of form, place and time
}

\author{
Joakim Wikner [0000-0003-2252-5337] $a$ a Fredrik Tiedemann ${ }^{[0000-0002-7190-9807]}$ \\ ${ }^{1}$ Jönköping University, Jönköping, Sweden \\ \{joakim.wikner, fredrik.tiedemann\}.ju.se
}

\begin{abstract}
The interest in customization has increased due to globalization, and globalization makes competing on price more difficult if access to low-cost production is unavailable. Customization usually implies the creation of variants, where the final products are customized in form, place and/or time. However, the relation between customization and variants is unclear; therefore, the purpose of this study is to analyze customization in terms of form, place and time, as well as relate it to product proliferation (i.e., variant creation). Here, a time perspective is used, creating a clear relation to flow thinking. Using flow thinking and the two strategic decoupling points related to flow driver (customer order decoupling point) and flow differentiation (customer adaptation decoupling point) provides a better understanding of what, where and when customization can be applied.
\end{abstract}

Keywords: customization, product proliferation, flow thinking, decoupling point

\section{Introduction}

The increase in globalization and offshoring of production to low-cost countries have led to greater pressure for cost reduction, especially on standardized products. In this context, the ability to offer customization can help offset the disadvantages of producing products in high-cost countries, for example. Customization usually implies a higher degree of product proliferation (i.e., introduction of variants), and although these concepts are closely related, there are some differences between them. However, this distinction is not always straightforward. Customization is a concept that is frequently used to distinguish between standardized and customized items. The pure cases are usually obvious, such as when a company designs and then produces a product based on a specific customer order or when a commodity is produced based on speculation and is stocked and sold in a retail store. However, when a modular product is designed so that it can be configured based on a customer order, using a predefined solution space, it is not as evident in the literature whether the product is standardized or customized. This example is related to the question of what is to be produced, that is, form. However, according to Debreu [1], an offering is characterized by not only its physical properties (form) but also where (place) and when (time) it will be available. Conse- 
quently, if place and time are included, more challenges arise in defining whether something is standardized or customized. A variant is also a more general term than customization since it is not bound to a direct (real) customer demand and may instead depend on the characteristics in the bill of materials (BOM). Therefore, the purpose of this study is to analyze customization in terms of form, place and time, as well as relate it to variants.

\section{Physical flow structures and time-phased flow structures}

Value is created in a network of activities, where input is transformed into output. This value creation is characterized by the resources used, flow control and flow structure, among others. The flow structure is of special interest in customization and variant creation. Nonetheless, as customer demand also covers when a demand arises in relation to the cumulative lead time, the time perspective is of interest as well.

Flow structures focusing on form and place are called physical flow structures. This type of structure involves different levels of abstraction; it is therefore necessary to decide on a specific level. The so-called AVX classification is often used in the material and capacity requirement literature [2]. This classification is based on the item level, where an item is perceived as indivisible, meaning that the activities (production or transportation) required to transform the item are abstracted and not considered. Instead, the focus is on the material structures (i.e., BOM), where the end product is at the top. The so-called VAT classification is similar, also includes resources and is found in the theory of constraints [3]. As such, VAT does not focus on items but on operations, resulting in a lower level of abstraction. The letters $\mathrm{V}$ and $\mathrm{A}$ in VAT correspond to the same letters in AVX, where T equals X, but the point of departure is the operation rather than the item. For both the AVX and the VAT structures, two flow structures (i.e., converging and diverging) make up the foundation, as illustrated in Table 1. For a converging flow, $\mathrm{B} 1$ and $\mathrm{B} 2$ are combined to obtain item $\mathrm{C}$; for a diverging flow, item $\mathrm{B}$ can result in $\mathrm{C} 1$ and/or $\mathrm{C} 2$. A converging flow consists of two or more flows joining in a point to form one flow, meaning that from an end product perspective, it is possible to move upstream the flow in order to identify all parts and raw material input of the flow. For diverging flows, the opposite occurs, where one must start from the raw material moving downstream to identify all parts of the flow and the end products. This means that it is difficult to relate to diverging flows from an end product perspective; instead, one should take a raw material perspective. Diverging flows can further be divided into two main types, namely attribute based and decision based. The attributebased type is passive, meaning that the end result is already given at the point of divergence, such as when a chemical process splits a raw material into two or more materials. The decision-based type is active, meaning that a decision can be made regarding what mix to create, usually termed variants. These three types of flow structures are summarized in Table 1. The interpretation of flow structures in terms of form transformation has already been discussed, but the place transformation has not yet been explained to the same extent. Essentially, it is about relating identity not only to what (form) but also to where (place), which is the meaning of the term stock-keeping unit (SKU). Place is 
therefore related to having something at one location (central) or at several locations (local). The place dimension is related more to active decisions rather than attributes.

Table 1. Combination of flow structures and form/place.

\begin{tabular}{|c|c|c|c|}
\hline \multirow{2}{*}{\multicolumn{2}{|c|}{ Converging }} & \multirow{2}{*}{\multicolumn{2}{|c|}{$\underset{\mathrm{C} 2}{\stackrel{\mathrm{x} 2}{\mathrm{C} 1}} \underset{\mathrm{Diverging} \text { (dec.-based) }}{\stackrel{\mathrm{x} 1}{\longrightarrow}}$}} \\
\hline & & & \\
\hline Form & Assembling or mixing & Splitting in a process & Creating variants \\
\hline Place & $\begin{array}{l}\text { Moving from local to cen- } \\
\text { tral warehouse }\end{array}$ & 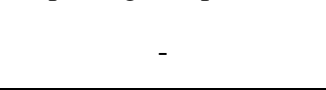 & $\begin{array}{l}\text { Moving from central to lo- } \\
\text { cal warehouse }\end{array}$ \\
\hline
\end{tabular}

Time (when) is another central property in transformation. Complementing form and place with time creates a representation of all three dimensions. One conventional way of doing this is through a time-phased BOM (see Fig. 1), which is usually illustrated horizontally to clearly illuminate the time dimension of the activities performed (in contrast to a traditional BOM). Each segment of the structure shown in Fig. 1 represents a transformation in terms of form and place. The time phasing means that each transformation step is offset by the corresponding time for each segment, that is, its lead time.

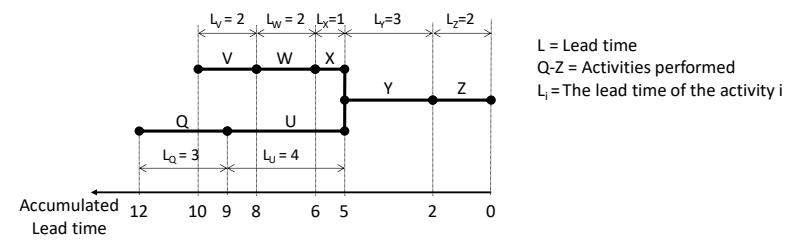

Fig. 1. Example of a time-phased flow structure (based on [4]).

The time-phased flow structure depicted in Fig. 1 represents the conditions in a given situation for a given point in time, that is, one state. Since the flow structures can adopt many different forms and combinations, it is difficult to define a generic space of states. Nevertheless, to sum up, this means that all transformations in the three dimensions need to be completed to create customer value. In other words, the demanded combination of form, place and time needs to be attained for the flow state to fulfil the requested state.

\section{Change of state through postponement and preponement}

Flow structures can be changed in several ways, but two concepts explicitly associated with change in form, place and time are postponement [see, e.g., 5, 6] and preponement [7]. The word 'postpone' means 'put off to a later time' [8]. Although 'prepone' is not found in the last cited reference [8], the prefix 'pre' means 'earlier than', 'prior to' or 
'before'. To postpone can thus be understood as to reposition to a later point in time, whereas to prepone means the opposite, to reposition to an earlier point in time. Both postponement and preponement are thus related to changes in an existing state, that is, repositioning an already existing position. Furthermore, both have their basis in the time dimension, meaning that a time-phased flow structure is a suitable point of departure. This also basically means that both terms are based on time and the repositioning of a transformation in relation to a fixed point of reference, which in this case is the customer's requested state. In this paper, the repositioning in time is called 'displacement' and is thus a collective term for postponement and preponement.

\subsection{Displacement of form, place and time}

Displacement of form and place transformation can occur by either creating new flow structures or changing the time required to perform the transformation activities. Table 1 indicates five different types of form and place conversions that can be achieved by displacement. From a form perspective, this means that through postponement, the form is achieved later in the flow (e.g., by modularization), using standardized modules instead of building complete unique products from scratch. In contrast, preponement could be used to create variants of a previously standard product.

Postponement of place transformation usually refers to differentiation in location at a later point in time, for example, by keeping products in a centralized warehouse instead of distributing them to local warehouses. This can be formulated as creating a variant in terms of a product's place property at a later point in time. Correspondingly, preponement means that the variant in terms of the place property is created at an earlier point in time to ensure local availability, for example.

Table 2. Combinations of displacement and form, place and time properties.

\begin{tabular}{|c|c|c|}
\hline & Preponement & Postponement \\
\hline Form & $\begin{array}{l}\text { Form variant created earlier in the flow } \\
\text { structure }\end{array}$ & $\begin{array}{l}\text { Form variant created later in the flow } \\
\text { structure }\end{array}$ \\
\hline Place & $\begin{array}{l}\text { Place variant created earlier in the flow } \\
\text { structure }\end{array}$ & $\begin{array}{l}\text { Place variant created later in the flow } \\
\text { structure }\end{array}$ \\
\hline Time & $\begin{array}{l}\text { Customer order decoupling point (CODP) } \\
\text { positioned earlier in the flow structure }\end{array}$ & $\begin{array}{l}\text { CODP positioned later in the flow } \\
\text { structure }\end{array}$ \\
\hline
\end{tabular}

Displacement of time seems as if time is counted twice, but here, the term time refers to two different things. Displacement has traditionally pertained to the change of the point in time when a transformation is carried out in relation to the requested delivery lead time [see, e.g., 9]. Displacement therefore conforms to the definition of the customer order decoupling point (CODP), based on how the delivery lead time relates to the system lead time [10]. The CODP is defined as the point that separates the forecastdriven part from the customer-order-driven part of the flow. To summarize, displacement, as well as form, place and time transformation, can be combined in six ways, as shown in Table 2. Basically, there are two types of changes in state. For form and place, 
the change is related to variants in flow, with an 'absolute' displacement since the displacement is made in time units. Time is then related to the flow driver and a relative displacement since the displacement occurs in relation to the delivery lead time. This also means that for form and place, the points of departure are the individual points of transformation in the flow. In contrast, for time, the point of departure is the CODP, which has its starting point in the delivery lead time.

\section{Customization and displacement}

Flow structures represent how the transformation of inputs to outputs is performed. The form and the place dimensions specify the type of transformation carried out, whereas the time dimension positions the different transformation activities in relation to each other. Together, these three dimensions can define a state of transformation. Displacement in terms of postponement and preponement then represents how a transformation can be changed, thus signifying a change of the pre-displacement state, which can have a different nature. Changes of form and place are structural in nature, but time is usually related to whether an exogenous customer demand drives the flow or if the flow is based on an anticipated future demand (i.e., a forecast). As such, displacement is intimately related to the CODP. This presents a general overview of how transformation can be described in terms of state and change. Even so, it does not include a distinction between standardized and customized activities. Different types of variants are included in the presented description, but it lacks a clear distinction of whether the variants are based on customer demand or something else.

\subsection{Customization in form, place and time}

Variants from the customer perspective tend to be associated with the distinction between standardized and customized products. Standardized refers to the customers' inability to influence the properties of a product that is offered to all customers (i.e., customer generic). In contrast, customization means that the product has some type of element adapted to a specific customer. From the form perspective, this means that a standard product is not based on an individual customer's requirements. Of course, this does not exclude the possibility of considering the market's expectations when designing the product. However, a customized product is based on individual customer requirements and is thus customer unique. Sometimes, the frequency of the demand is also considered, distinguishing between customer-unique and delivery-unique types. For the latter, the ordered product is obviously unique for a specific customer order, but a customer-unique item could be ordered several times by the same customer.

A comparable reasoning can be stated in terms of the place perspective. A standardized place implies that customers can retrieve their products from a specific place, such as a central or a local warehouse. A customer-unique place should then correspond to a delivery made to a specific postal address, that is exclusively the customer's own location. For the form, the question of frequency is raised, but this does not have the same meaning for the place. The place is more of a grey scale between the completely 
standardized place, where the product receives its final form, and the customized place, where the product is used. In between them, a number of places are neither completely standardized nor completely customized but intermediate. The two perspectives can be summarized as shown in Table 3, where the columns indicate the degrees of customization in terms of form $(\mathrm{F})$, and the rows present the degrees of customization in terms of place (P). To distinguish among different degrees of uniqueness, various types of strategic decoupling points have been introduced, one being the customer adaptation decoupling point (CADP) [see, e.g., 4, 10, 11]. This means that the top left combination is a complete standardized product, and the bottom right combination is a complete customized product in terms of both form and place. All other combinations are some forms of intermediate products. The CADP is positioned in between customer-unique and customer-order-unique types, and as it relates to form, it can be denoted as CODPF. Similarly, a CADP can be defined for the place dimension, denoted as $\operatorname{CODP}_{\mathrm{P}}$, which is correspondingly positioned in between intermediate and local types.

Table 3. Customization of form (F) and place (P).

\begin{tabular}{lccc}
\hline & F: Customer generic & F: Customer unique & F: Delivery unique \\
\hline P: Central & Standardized & & \\
P: Intermediate & & & \\
P: Local & & Customized \\
\hline
\end{tabular}

Customization of form and place can be viewed as a scale ranging from standardized to customized, regardless of whether form or place is considered separately or in combination. This distinction between standardized and customized has a long history and is sometimes associated with the driver and the CODP. By combining the driver with uniqueness, as presented in Table 4, four possible combinations are obtained. Case I represents situations where standardized products are made based on forecasts (i.e., standardization is usually associated with activities upstream of the CODP). Case III is the other extreme case where customized products are made due to a commitment to a customer order (i.e., customization is usually associated with activities downstream of the CODP). When the CODP is used to define both uniqueness and flow driver, no more combinations can be found. If the typology is instead aligned with assumptions in $[4,10,11]$, the CODP is only related to the flow driver, whereas the CADP is used for the flow differentiation. By using the CADP, one more relevant combination can be found, namely standard products made due to a commitment to customer orders, that is, Case II (see Table 4). However, since customization should not be carried out based on a forecast (speculation), the fourth logical combination is perceived as undesirable and thus considered not applicable (N/A).

Table 4. Combinations of driver and uniqueness (based on $[4,11]$ ).

\begin{tabular}{lcc}
\hline & Forecast-driven & Customer-order-driven \\
\hline Standardized & Case I & Case II \\
Customized & N/A & Case III \\
\hline
\end{tabular}




\section{$5 \quad$ Summarizing customization and displacement}

Customization can thus be described as a combination of three dimensions: (1) Regarding form, customization answers the question of what and is related to the $\mathrm{CADP}_{\mathrm{F} .}$ (2) As for place, customization answers the question of where, related to the CADP $\mathrm{P}_{\mathrm{P}}$ (3) Concerning time, the flow driver answers the question of when, related to the CODP. Customization can thus be described as a state with three dimensions. A product delivery is thereby a combination of the flow driver in time and the flow differentiation (customization) in form and place. Note that this state is only one subset of the possible states defined as variants, where only a portion is related to 'real' customer demand. Changes in the state of variants can then be made using displacement (i.e., postponement or preponement), meaning that one state (S1) transitions into another state (S2), as illustrated in Fig. 2. Note that $\mathrm{S} 1$ and $\mathrm{S} 2$ could signify that the same customizations are offered in two different ways, as shown in Fig. 2, or that two different types of customizations are offered. Two examples of states for a structure are illustrated in Fig. 2. In the left part, $\mathrm{S} 1$ indicates that $\mathrm{B}$ can be used for creating either $\mathrm{C} 1$ or $\mathrm{C} 2$. A postponement of the variant proliferation point (CADP) would result in $\mathrm{S} 2$, where $\mathrm{C}$ is kept 'generic' and could be used for creating either X1 or X2. Both structures thus mean that $\mathrm{X} 1$ and $\mathrm{X} 2$ are created but in two different ways, where S2 means that the customization can be made at a later point in the structure, enabling a shorter delivery lead time.

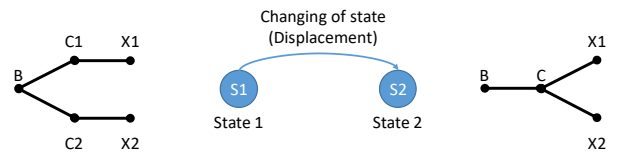

Fig. 2. Customization and displacement (based on [10]).

Changing the state in flow structures with a focus on customization brings several challenges. Instead of focusing on form, place and time, the points of departure here are the three types of decoupling points, see in Table 5. Note that the three decoupling points are not independent of each other in creating customization. Unlike the general concept of variants, customization in form, place and time has a point of reference in terms of the customer order. Rational customization requires that a customer order has been received; thus, the CODP constitutes a restriction of how far upstream the $\mathrm{CADP}_{\mathrm{F}}$ and the $\mathrm{CADP}_{\mathrm{P}}$ should be positioned in a time-phased flow structure. Displacement of 'form and time' and 'place and time', as shown in Table 5, therefore means that form and place are each shifted in time where time is included. Customization in terms of form has traditionally been created in a factory before the product is delivered to a customized place. This means that the $\mathrm{CADP}_{\mathrm{F}}$ traditionally is positioned before the $\mathrm{CADP}_{\mathrm{P}}$ in the flow. However, new technology, such as additive manufacturing using three-dimensional printing, has enabled customization in form to be created closer to the customers.

Table 5. Decoupling points and displacement.

\begin{tabular}{lc}
\hline Decoupling point & Changing state (Displacement) \\
\hline CADPF & Displacement of form and time, CADPF should not be upstream of CODP \\
CADPP & Displacement of place and time, CADPP should not be upstream of CODP \\
CODP & Time postponement or time preponement \\
\hline
\end{tabular}




\section{Conclusions}

The purpose of this study is to analyze customization in terms of form, place and time, as well as relate it to variants. The main conclusion drawn from this study is that both customization and variants are related to flow states, represented by flow structures. A state can be defined in terms of the three dimensions: form, place and time. With their relations to different strategic decoupling points and through the three dimensions, strategies such as postponement and preponement can also be identified as forms of support for changes in a state. Using flow thinking [10] and the two strategic decoupling points (CODP and CADP) provides a better understanding for the questions of what, where and when customization can be applied. Hence, this study contributes to the existing literature by increasing the knowledge of what can be considered standard variants and customization, respectively. Further research could include theoretical development, for instance, where the relationship among postponement, preponement and flow thinking could be more clarified. Practical applications could also be further examined, where the understanding of displacement improves the capability to manage operational development, enabling more effective and efficient flow solutions.

\section{Acknowledgement}

This research has been conducted under the KOPtimera project, funded by the Swedish Knowledge Foundation and Jönköping University.

\section{References}

1. Debreu, G.: Theory of value: An axiomatic analysis of economic equilibrium. Yale University Press, London (1987).

2. Oden, H., Langenwalter, G., Lucier, R.: Handbook of material and capacity requirements planning. McGraw-Hill, New York, NY (1993).

3. Umble, M.M., Srikanth, M.L.: Synchronous management: Profit-based manufacturing for the 21st century. Vol. 2. The Spectrum Publishing Company, Guilford, CT (1997).

4. Wikner, J.: On decoupling points and decoupling zones. Production \& Manufacturing Research 2(1), 167-215 (2014).

5. Alderson, W.: Marketing efficiency and the principle of postponement. Cost and Profit Outlook 3(4) (1950).

6. Bucklin, L.P.: Postponement, speculation and the structure of distribution channels. Journal of Marketing Research 2(1), 26-31 (1965).

7. Blackburn, J.D., Guide Jr, V.D.R., Souza, G.C., Van Wassenhove, L.N.: Reverse supply chains for commercial returns. California Management Review 46(2), 6-22 (2004).

8. Merriam-Webster, https://www.merriam-webster.com/, last accessed 2019/02/06.

9. Forza, C., Salvador, F., Trentin, A.: Form postponement effects on operational performance: A typological theory. International Journal of Operations \& Production Management 28(11), 1067-1094 (2008).

10. Wikner, J.: An ontology for flow thinking based on decoupling points - unravelling a control logic for lean thinking. Production \& Manufacturing Research 6(1), 433-469 (2018).

11. Wikner, J., Bäckstrand, J. Decoupling points and product uniqueness impact on supplier relations. Paper presented at EurOMA 2012 - P\&OM 4th World Conference, 1-5 July. Amsterdam (2012). 